\title{
Oil Sorption Performance of Sorbent Materials Examined Under Static and Dynamic Conditions
}

\author{
Emmanuel E. Anwana and Oluseyi E. Ewemoje
}

\begin{abstract}
Oil spill cleanup and subsequent restoration of the environment is majorly a function of spill cleanup methods applied. Some of these methods, though efficient, are, however, very expensive and require more personnel for their application and relative deployment in the field. The study was aimed at examining the efficiency of a locally and readily available, ecofriendly and low cost agricultural waste (coconut husk coir) as sorbent materials for spilled engine oil cleanup under static and dynamic marine water conditions. The sorbent material was prepared and used in three forms: raw coconut husk coir (CHC), modified coconut husk coir (MCHC), and reused coconut husk coir (RCHC). Under static and dynamic marine water conditions, oil sorption batch equilibrium experiments were used to study the engine oil sorption capacity and efficiency of the sorbent. Effects of sorbent dosage and sorption times on the oil sorption and efficiency of $\mathrm{CHC}$, MCHC, and RCHC were studied and determined. At a constant sorption time of 60 minutes and varying sorbent dosages of $2-8 / 320 \mathrm{ml}$ of engine oilmarine water concentration, MCHC exhibited the highest oil sorption efficiency of $61.18 \%$ and $44.33 \%$ for dynamic and static condition, CHC had $55.61 \%$ and $38.50 \%$ for dynamic and static conditions, whereas RCHC had $41.66 \%$ and $26.04 \%$ for dynamic and static conditions, respectively. It is statistically deduced from the results that sorption times and sorbent dosages have significant effects on the sorption efficiency of experimental coir for spilled engine oil removal. Though there is a need for proper blending or modifications of the sorbent material to enhance its affinity to oil and hydrophobicity, there are enough potentials in the materials for mild marine water current spilled engine oil cleanup.
\end{abstract}

Index Terms - Engine Oil, Hydrophobicity, Oil Sorption, Sorbent Material, Static and Dynamic Conditions.

\section{INTRODUCTION}

Industrialization and urbanization together with their attendant rapid population growth are among major indices of development which increase daily demands for reachable energy sources. Fossil fuel as a non-renewable energy source is among the most widely used. The process of fossil fuel exploration, production, storage, and transportation catalyzed by the growing-population high demand for oil often result in some adverse impacts on the environment, economy, humans, and biota [1], [2]. The environment in consideration could be arboreal, terrestrial, or aquatic. Among the adverse impacts of these fossil fuel activities is the spillage on earth, over the sea and other useful water bodies as well as surfaces.

The introduction of virgin oil through pipelines vandalism, truck and equipment breakdown, operational failure, and

Submitted on June 06, 2021.

Published on August 13, 2021.

E. E. Anwana, Department of Agricultural and Environmental Engineering, Faculty of Technology, University of Ibadan, Nigeria.

(e-mail: emmetan4all@yahoo.com) natural occurrences as well as indiscriminate disposal of used and contaminated hydrocarbon products, lowers the quality of the biosphere thus deteriorating habitable lives therein. In water environment, oil spillage affects suitability of surface water for drinking, irrigation, and survival of aquatic lives. The oil sheen and slick on the water surface makes the water undrinkable, and affects the availability of dissolved oxygen, thus poses a negative influence on the ecosystem as marine lives are put at high risk and oil slick affects soil aeration process [3]. It is necessary to clean the water or land immediately such spillage occurs [4] to avoid pollution of the area [5]. In restoring and recovering an oil polluted environment, some quick oil spill cleanup methods are employed.

According to [6], there is no simple procedure which can be recommended for all spills as spilled oil is known to behave differently depending on the type of oil, the surface on which it spills, the soil type and sub soil conditions, and the prevailing weather conditions. Hence, the choice of cleaning method must take into account these factors.

However, in the case of water environment, oil spill response techniques such as chemical, physical, and biological methods are often employed by oil exploration companies in the event of spillage. These methods are time consuming, have high cost of operations and require a lot of personnel as well as equipment to successfully recover the ecosystem. In the event where neither the government nor exploration company can be reached immediately, victims should be able to proffer temporary and immediate solution to forestall escalation. This calls for redirecting focus on the exploring eco-friendly and low cost alternatives [7].

Relevant studies have been carried out to research into the capacity of some environmentally friendly, hydrophobic, oleophilic, low cost, readily available and biodegradable sorbent materials as alternative to chemical and mechanical methods of oil spill cleanup. Some examples of such studies include but not limited to the following: use of cotton product and kenaf as oil sorbent [8]; Evaluation of kapok as natural hollow hydrophobic-oleophilic fibrous sorbent for oil spill cleanup [9]; preparation and evaluation of fatty-sawdust as a natural biopolymer for oil spill sorption [10]; use of human hair as natural oil spill sorbent [11].

This research work was therefore performed to examine the applicability of coconut husk coir as engine oil spill cleanup sorbent under static and dynamic marine water conditions.

O. E. Ewemoje, Department of Agricultural and Environmental Engineering, Faculty of Technology, University of Ibadan, Nigeria.

(e-mail: oluseyi.ewemoje ${ }^{\circledR}$ mail.ui.edu.ng) 


\section{MATERIALS AND METHODS}

Marine water used for the study was obtained from Alpha River, Aja, Lagos, Nieria. SAE 40 heavy duty oil used for the study was obtained from a local motor oil shop, Ajibode. Ibadan, Nigeria. Physical properties of engine oil were analyzed at the Core Preparation and Drilling Laboratory, University of Ibadan, Nigeria. The raw coconut husk (Fig. 1) used for the study was sourced from Bodija Market, Ibadan, Nigeria.

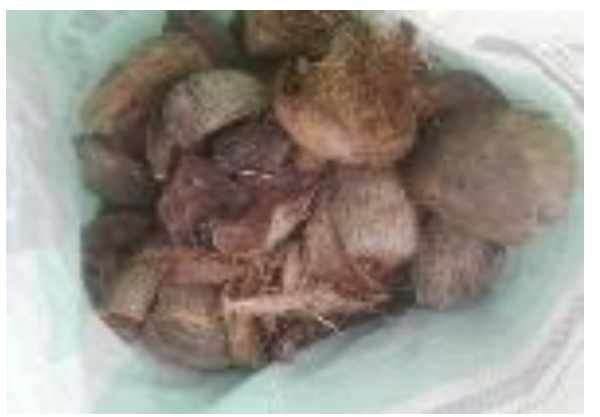

Fig. 1. Raw coconut husk (coir precursor).

The outer cover of the husk was manually removed to obtain the soft inner fibre called coir (Fig. 2). The coconut husk coir (CHC) was pulverized, soaked, and washed [12] with detergent to remove impurities capable of increasing and causing secondary contamination of the marine water used for the study.

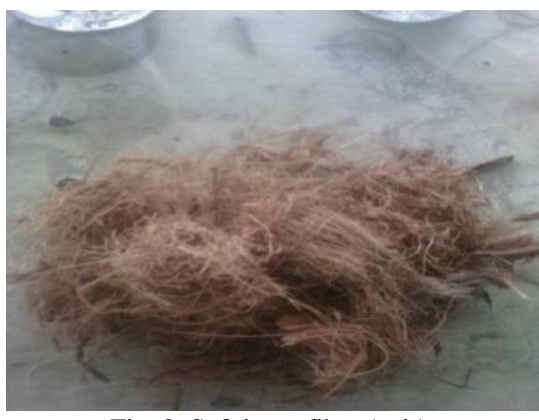

Fig. 2. Soft inner fibre (coir).

The macerated $\mathrm{CHC}$ was then sun dried for 3 days and later oven dried at $60{ }^{\circ} \mathrm{C}$ for 2 hours. Modified coconut coir (MCHC) was prepared by impregnating raw with artificial human hair in a ratio of $2: 1$. Raw coconut husk which was later reused for the sorption batch equilibrium experiment was prepared using soxhlet extraction method for desorption process.

The Fourier Transform Infrared (FT-IR) Spectroscopy used during the study was to identify functional groups present in coconut husk which enhance the adsorption ability of the adsorbent. A bench scale batch sorption equilibrium experiments were performed to ascertain the how adsorbent dosages affect the engine oil sorption capacity of the coconut husk coir from the marine water at room temperature. The investigation of these effects was studied under two marine water conditions: static and dynamic conditions. For the static condition, $300 \mathrm{ml}$ of seawater was measured into four $600 \mathrm{ml}$ beakers placed on the bench (Fig. 3).

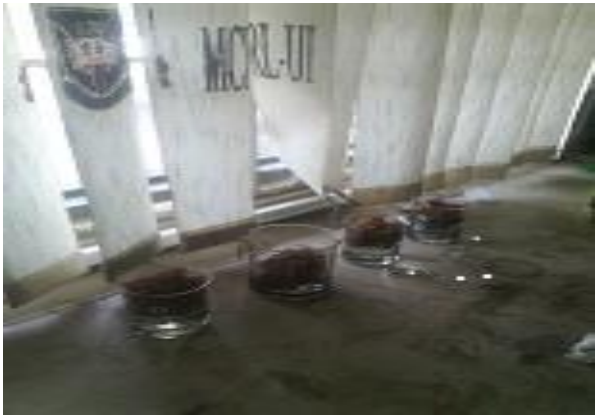

Fig. 3. Simulated static engine oil sorption condition.

A circular $1 \mathrm{~mm}$ net size with a thread at both edges was carefully suspended into the beaker containing designed volume of water. $20 \mathrm{ml}(17.04 \mathrm{~g})$ engine oil spill was simulated on the surface of seawater in the beakers. $2 \mathrm{~g}$ of raw coconut husk coir made to have almost a flat surface was carefully deployed into the beakers, after 60 minutes' sorption time, the wet adsorbent was harvested from the test cells using the net submerged into the beakers.

The harvested sorbent was suspended for two minutes to allow passively adsorbed engine oil and water to drain [13]. Once it was 2 minutes, the macerated sorbent was weighed and then placed in an oven for 10 minutes at $50{ }^{\circ} \mathrm{C}$ [14]. After 10 minutes, sorbent was then weighed to obtain weight of oil adsorbed. After the weight was recorded, sorbent was placed in sample bags for desorption and reused. The entire procedures were repeated for 4, 6 and $8 \mathrm{~g}$ of raw, modified, and reused coconut husk coir.

However, for dynamic condition, test cells were rather mounted on start mechanical orbital shaker (Fig. 4) and allowed to run at $105 \mathrm{rev} / \mathrm{min}$ for 60 minutes [13]. The means of replicate were used for calculations.

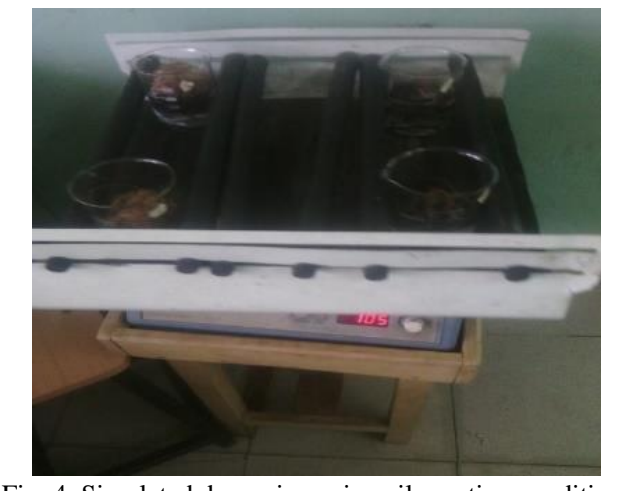

Fig. 4. Simulated dynamic engine oil sorption condition.

The percentage of oil removal was calculated using the expression in Equation (1) according to [15] as:

$\%$ of oil sorption $=\frac{C_{o}-C_{e}}{C_{o}} \times 100$

where

$C_{o}$ - Initial Concentration of adsorbate $(\mathrm{g})$;

$C_{e}$ - Concentration of adsorbate at equilibrium.

\section{RESULTS AND DISCUSSION}

The values of density, specific gravity, viscosity, and API gravity of the engine oil used for the study, determined at 
room temperature were: $0.935 \mathrm{~g} / \mathrm{cm}^{3}, 0.88,1.30 \mathrm{gs} / \mathrm{cm}^{3}$ (Oswald viscometer size 450) and 29.30 API, respectively. The lower density of engine oil than that of water made it possible for engine oil to float on the experimental seawater surface used for the study.

\section{A. Functional Group Analysis of Sorbent}

Fig. 5, Fourier Transform Infrared spectroscopy of the experimental adsorbent indicated that coconut husk coir exhibits its strong bans at $3436 \mathrm{~cm}^{-1}$ due to $-\mathrm{OH}$ stretching.

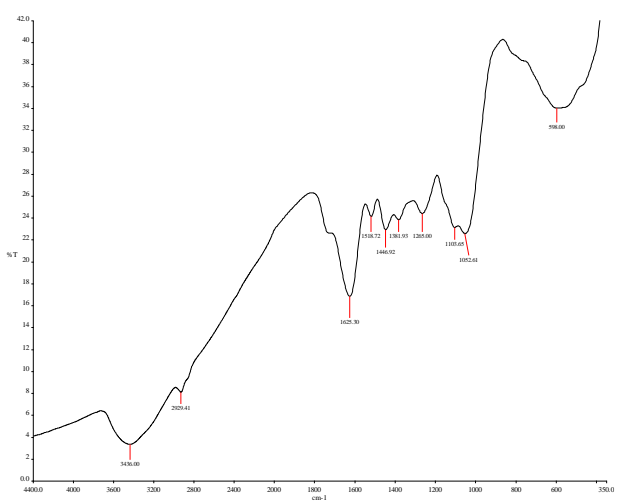

Fig. 5. FT-IR of coconut husk coir.

From Fig. 5, there are two outstanding peaks: $2929 \mathrm{~cm}^{-1}$ and $1625 \mathrm{~cm}^{-1}$. According to [16], the peak at $2929 \mathrm{~cm}^{-1}$ corresponds to $\mathrm{C}-\mathrm{H}$ asymmetric stretching of $\mathrm{CH}_{2}$ group, whereas the peak at $1625 \mathrm{~cm}^{-1}$ is attributed to $\mathrm{H}-\mathrm{O}-\mathrm{H}$ bonding. The available functional groups have great affinity for hydrocarbon solvent.

B. Engine Oil Sorption Efficiency of Coconut Husk coir as Studied under Static and Dynamic Oil Sorption Conditions.

Table I shows the oil uptake efficiency of the experimental sorbent. From the table, MCHC, CHC and RCHC have engine oil efficiencies of $12.30 \%$ and $23.80 \%, 10.27 \%$ and $19.84 \%, 9.68 \%$ and $13.26 \%$ for static and dynamic conditions respectively using sorbent dosage of $2 \mathrm{~g}$ at constant sorption time of 60 minutes.

TABLE I: EFFECTS OF ADSORBENT DOSAGE ON ENGINE OIL SORPTION

\begin{tabular}{cccc} 
& \multicolumn{3}{c}{ EFFICIENCY } \\
\hline \hline \multirow{2}{*}{$\begin{array}{c}\text { Adsorbent } \\
\text { Category }\end{array}$} & \multirow{2}{*}{\begin{tabular}{c} 
Dosage \\
\cline { 3 - 4 } CHC
\end{tabular}} & Oil Sorption Efficiency $(\%)$ \\
\hline & 2.00 & 10.27 & 19.84 \\
& 4.00 & 17.97 & 35.29 \\
& 6.00 & 27.01 & 46.58 \\
& 8.00 & 38.50 & 55.61 \\
\hline \multirow{3}{*}{ MCHC } & 2.00 & 12.30 & 23.80 \\
& 4.00 & 21.55 & 42.62 \\
& 6.00 & 32.51 & 55.88 \\
& 8.00 & 44.33 & 61.18 \\
\hline \multirow{2}{*}{ RCHC } & 2.00 & 9.68 & 13.26 \\
& 4.00 & 11.68 & 25.40 \\
& 6.00 & 18.18 & 32.73 \\
\hline \hline
\end{tabular}

$\mathrm{CHC}$ is coconut husk coir, $\mathrm{MCHC}$ is modified coconut husk coir, and RCHC is reused coconut husk coir. It is also shown in the table that $\mathrm{MCHC}, \mathrm{CHC}$ and $\mathrm{RCHC}$ have engine oil efficiencies of $21.55 \%$ and $42.62 \%, 17.97 \%$ and $35.29 \%$, $11.68 \%$ and $25.40 \%$ for static and dynamic conditions respectively using sorbent dosage of $4 \mathrm{~g}$ at constant sorption time of 60 minutes. At the same constant sorption time of 60 minutes, sorbent dosage of $6 \mathrm{~g}$ has $32.51 \%$ and $55.88 \%, 27.01$ and $46.58 \%, 18.18 \%$ and $32.73 \%$ engine oil sorption efficiencies for $\mathrm{MCHC}, \mathrm{CHC}$ and $\mathrm{RCHC}$ under static and dynamic conditions respectively.

The results revealed that for sorbent dosage of $8 \mathrm{~g}$ being the highest experimental sorbent dosage at constant sorption time of 60 minutes, raw coconut husk coir was able to adsorb up to $50 \%$ of the total engine oil simulated as spill on the marine water surface. However, modified coconut husk coir, MCHC had the highest engine oil sorption efficiencies of $61.18 \%$ for dynamic condition and $44.33 \%$ for static condition at $8 \mathrm{~g} / 320 \mathrm{ml}$ of oil-water concentration and constant sorption time of 60 minutes.

From Fig. 6, for sorbent dosages of 2-8 g, there was an increasing engine oil sorption efficiency for all experimental sorbents (MCHC, $\mathrm{CHC}$ and $\mathrm{RCHC}$ ). MCHC had increased engine oil sorption efficiencies of $12.30-44.33 \%$, CHC had 10.27-38.50\% and RCHC had 9.68-26.04\%.

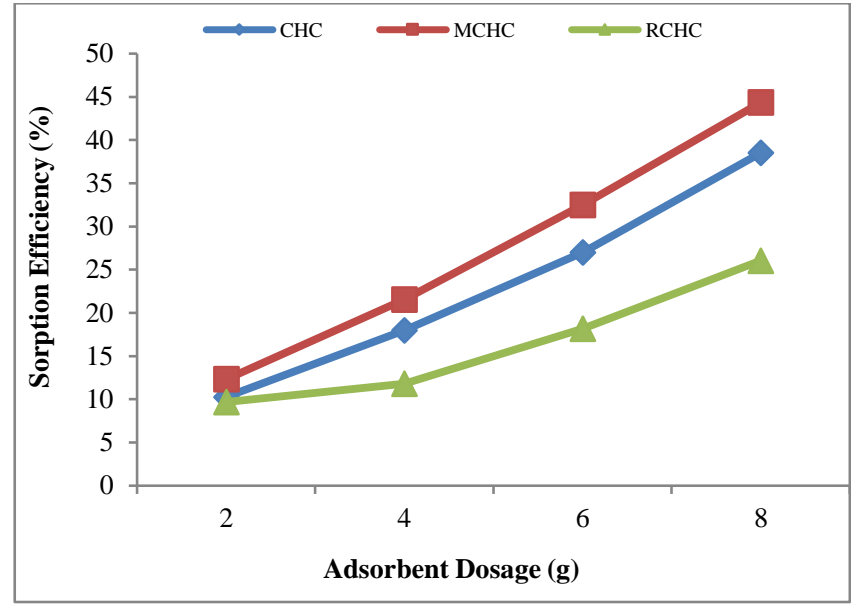

Fig. 6. Effects of adsorbent dosage on engine oil sorption efficiency under static condition.

The results as shown in Fig. 6 and 7 revealed that engine oil sorption efficiency of experimental sorbent increases with increasing sorbent dosages for both static and dynamic sorption conditions. The results agree with the work of [11]. The observed increasing engine oil sorption efficiencies can be attributed to the fact that the higher the adsorbent dosage, the higher the number of active bare adsorption sites in the adsorbent.

As observed from Fig. 7, for sorbent dosages of 2-8 g, there was an increasing engine oil sorption efficiency for all experimental sorbents ( $\mathrm{MCHC}, \mathrm{CHC}$ and $\mathrm{RCHC}$ ).

$\mathrm{MCHC}$ had increased engine oil sorption efficiencies of $23.10 \%$ to $61.18 \%$. However, between $6-8 \mathrm{~g}$ of sorbent dosages, there was about $5.5 \%$ drop in engine oil sorption efficiency of MCHC. This could be likened to a nearequilibrium situation. From Fig. 6 and 7, the experimental sorbent materials have higher sorption efficiencies for dynamic condition than static condition. This could be attributed to the more adsorption active sites and higher surface area covered by the sorbent material for dynamic condition than static condition. 


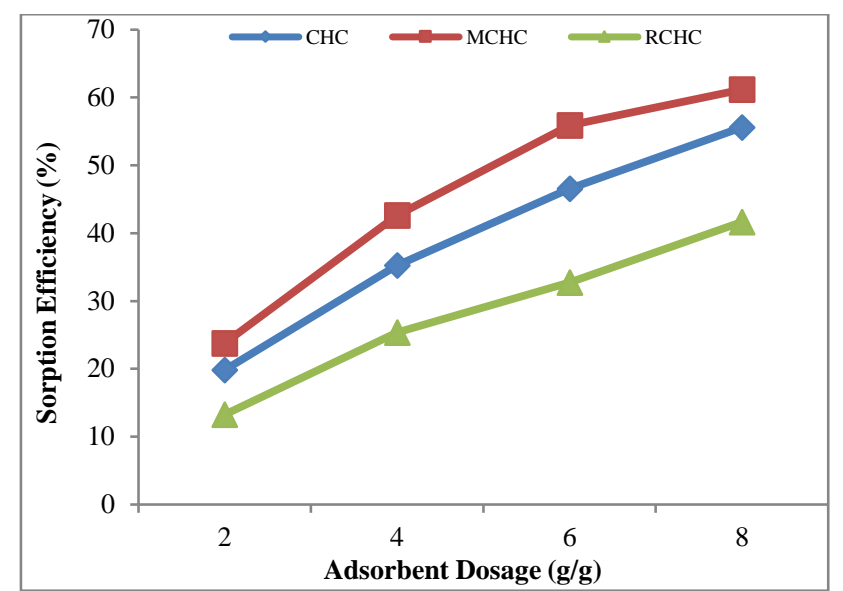

Fig. 7. Effects of adsorbent dosage on engine oil sorption efficiency under dynamic condition.

\section{CONCLUSION}

1. Coconut husk coir has $-\mathrm{OH}$ and $\mathrm{C}-\mathrm{H}$ functional groups believed to give it the huge applicability for spilled engine oil clean up.

2. Appropriate blending of the sorbent with a more oleophilic and hydrophobic materials, will yield a more positive result for cleaning spilled engine oil from seawater surface.

3. The material is more efficiently for mild water current (dynamic) condition than static condition.

4. Coconut husk coir has potentials for reusability as demonstrated in the study.

\section{DECLARATION OF COMPETING INTEREST}

The authors are certain that there are no known conflicting interests associated with the publications and there is no significant financial support for this work that could warrant any influence on its outcome.

\section{ACKNOWLEDGEMENT}

The authors acknowledge Engr. Asuquo Edet Inuikim of NNPC and Mr. Bola Adebanjo of Petroleum Engineering Department, University of Ibadan, Nigeria, for their contributions to the success of this work.

\section{FUNDING}

The study did not receive funding in any form from any funding Agency.

\section{REFERENCES}

[1] Solomon, G. M. and Janssen, S. (2010). Health Effects of the Oil Spill, JAMA: The Journal of the American Medical Association, Vol. 304, pp. 1118-1119.

[2] Chen, J. and Denison, M. S. (2011). The Deepwater Horizon Oil Spill: Environmental Fate of the Oil and the Toxicological Effects on Marine Organism, Journal of Young Investigators, Vol. 21, pp. 84-95.

[3] Idris, J., Eyu, G. D., Ahmad, Z., Chukwuekezie, C.S. (2013). Oil Spills and Sustainable Clean Up Approach, Austrialian Journal of Basic and Applied Sciences, Vol. 7(14), pp. 272-280.

[4] Rengasamy, R., Das, D. and Praba Karan, C. (2011). Study of Oil Sorption Behavior of Filled and Structured Ffiber Assemblies made from Polypropylene, Kapok and Milkweed, Journal of Hazardous Materials, vol. 186, pp. 526-532.

[5] Wei, Q. F., Mather, R. R. and Fotheringham, A. F. (2005), Oil Sorbent, Journal of Oil Gas Science and Technology, Vol 62, pp. 407.

[6] Al-Majed, A. A., Adebayo, A. R., Hossain, M. E. (2012). A Sustainable Approach to Controlling Oil Spills, Journal of Environmental Management, Vol. 113, (2012), pp. 213-227.

[7] Choi, H.M., and Cloud, R.M. (1992). Use of natural sorbents for oil spill cleanup, Environmental Science and Technology, 26(4), pp. 772 776.

[8] Anthony, W. S. (1994). Absorption of Oil with Cotton Products and Kenaf. Appl. Eng. Agri., Vol.10, pp. 357-361.

[9] Lim, T. and Huang, X. (2007). Evaluation of Kapok (Ceiba Pentandra (L.) Gaertn.) as a natural Hollow Hydrophobic-oleophilic Fibrous Sorbent for Oil Spill Cleanup, Chemosphere, vol. 66, pp. 955-963.

[10] Ismail, A. S. (2015). Preparation and Evalution of Fatty-sawdust as a Natural Bio polymer for Oil Spill Sorption, Chemistry Journal, Vol 5(5), pp. 80-85.

[11] Ukotije-Ikwut, P. R., Idogun, A. K., Iriakuma, C.T., Aseminaso, A., Obomanu, T. (2016). A Novel Method for Adsorption using Human Hair as a Natural Oil Spill Sorbent, International Journal of Scientific and Engineering Research, Vol. 7(8), pp 1754-1764.

[12] Ifelebuegu, A. O. and Momoh, Z. (2015). Evaluation of the adsorptive properties of Coconut Husk for Oil spill cleanup. Proceedings of International Conference on Advances in Applied Science and Environmental Technology.

[13] ASTM 1998c, F726-99: Standard Test Method for Sorbent Performance of Adsorbents in: Annual Book of ASTM Standards, ASTM committee on Standards, West Conshohocken, PA, 1998.

[14] Ali, N., Rehan, A. M., Hussain, A., Memon, H. (2014), Investigation of Chemically Modified Banana Fibers for the Sorption of Oil from Aqueous Solution, WARP, Vol. 2014, p 2-5.

[15] Abdul Hamid, N. S., Malek, N. A. C., Mokhtar, H., Mazlan, W. S., Tajuddin, R. M. (2016) Removal of Oil and Grease from Wastewater using Natural, Journal Teknologi (Science and Engineering), Vol.78(53), pp. 97-102.

[16] Banerjee, S.S. (2006). Treatment of oil spill by sorption technique using fatty acid grafted sawdust, Chemosphere, 200608, 64(6), 10261031 . 